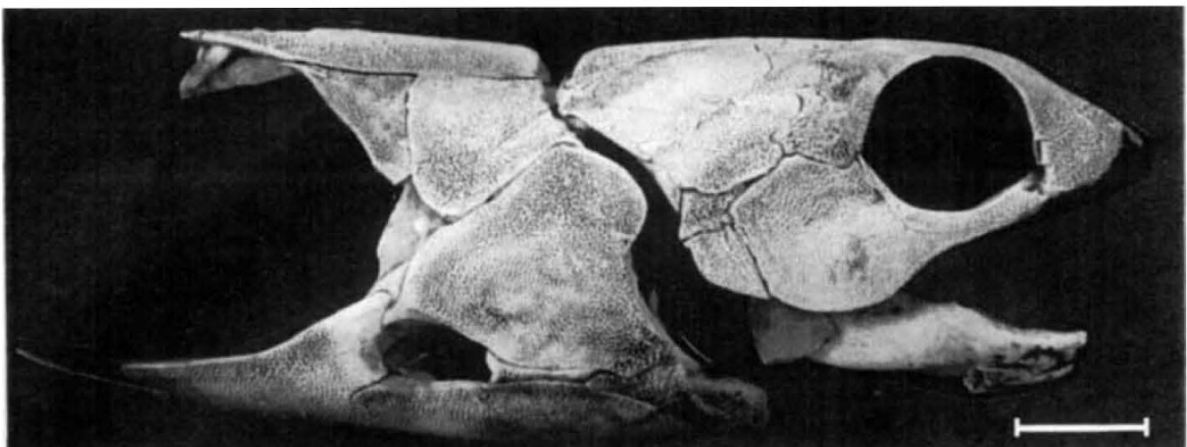

Fig. 2 Latocamurus coulthardi, a new species from Gogo reported by Long ${ }^{\prime}$. Bar, $1 \mathrm{~cm}$.

shape, and the spaces for the tissues are perfectly preserved inside the skull. As the rock is calcareous, it can be dissolved away from the bones with dilute acetic acid. This technique is rapid and delicate, yielding specimens which are comparable in quality with present-day skeletons. Three-dimensional fossil-fish specimens are often studied by serial grinding, where the fossil is 'sectioned' by grinding it away, and the 'sections' are used as templates for a large wax model of the specimen. This method yields a detailed picture, but destroys the fossil, and translation from sections to a wax model is a potential source of error. In an acid-prepared specimen from Gogo, on the other hand, the original anatomical structures are clearly visible, and the quality of preservation means that virtually no reconstruction or interpretation is needed. It is this degree of objectivity which makes the Gogo fossils invaluable.

In the first of his new papers ${ }^{1}$, Long describes a new genus of placoderm, an extinct group of armoured fishes whose jaws were armed with bony shearing blades rather than normal teeth (Fig. 2). In the newly discovered form, the fragile anterior part of the braincase is perfectly preserved, so the exact relationship between this structure and the superficial bones can easily be reconstructed. The relationships of the placoderms are uncertain: opinions vary as to whether they are related to sharks and ratfishes, to osteichthyans (bony fishes), or whether they are the most primitive jawed vertebrates.

Another controversy fuelled by evidence from the Gogo fossils concerns the origin of tetrapods. It is clear that these animals evolved from one of the 'lobe-finned' bony fish groups, but at present there is a vigorous debate about the exact relationship. The traditional view links tetrapods with the extinct osteolepiform fishes, but Rosen et al. in 1981 claimed instead that lungfishes are the closest relatives of tetrapods ${ }^{3}$. Their reinterpretation focused on the choana, the internal nostril which in tetrapods opens from the nasal sac into the mouth. As this structure is absent in most fishes, including some of the lobefins, any fish with a choana must be related to tetrapods. Modern lungfishes have an internal nostril, and the grinding method reveals that osteolepiforms have a canal leading from the nasal sac to the palate in the correct region ${ }^{4}$ - both groups could therefore be choanate. But the tetrapod choana is always surrounded by a particular set of bones present in osteolepiforms but absent in modern lungfishes, and this has been taken as evidence that the lungfish internal nostril is not a choana.

Some of the Gogo lungfishes have internal nostrils surrounded by bones ${ }^{5}$. Gardiner and Rosen independently realized that these bones could be the same as those of tetrapods, and that the internal nostril could, after all, be a true choana. This led to their reassessment ${ }^{3}$ of the evidence for a tetrapod-osteolepiform relationship, and their rejection of many of the characters supposedly uniting the two groups. Notably, they rejected the view that osteolepiform fishes were choanate - the size of the supposed choana seemed too variable, and the serial grinding method on which the reconstructions were based left too much room for error. Their conclusions have been fiercely debated $^{\circ}$, despite the lack of new anatomical data since Rosen et al. published their conclusions. Long's second new paper $^{2}$ provides that evidence. He describes a new osteolepiform fish from Gogo. This fossil definitely has an opening on the palate large enough to have contained a nostril, supporting the original interpretation that the serially ground osteolepiforms are related to tetrapods.

The controversy has not yet been resolved, and in any case it is only one of many debates about vertebrate relationships. To solve these problems, detailed information is needed about the anatomy of fossil vertebrates, information which can be gained only from exceptionally well-preserved specimens. The Gogo fossil fishes provide such information; their scientific value is incalculable.

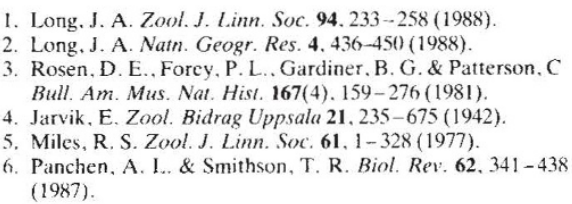

Per Ahlberg is in the Department of Zoology University of Oxford, South Parks Road Oxford OX1 $3 P S, U K$
Daedalus

\section{Real dry cleaning}

WASHING is ridiculously inefficient. Grams of detergent and kilograms of hot water are energetically agitated in order to remove a few milligrams of dirt; and the whole mixture is then just thrown away.

Seeking a better process, Daedalus recalled those wonderfully repulsive children's toys made of a highly plasticized and very sticky rubber. When dropped on a typical kitchen floor, they adhere strongly and then slowly peel off, bearing a fine catch of crumbs, dust, fluff and hairs. But as dirt-removers, they only shift the problem along: the manufacturers advise you to wash them clean with soap and water.

So DREADCO's chemists are extending the principle. They are experimenting with derivatives and analogues of gelatine, plasticized with water into a highly elastic gel. The addition of a suitable viscous hydrophilic polymer for stickiness, and a detergent to bind dirt particles, gives a new consumer product: DREADCO's Dry Soap. A cylinder of Dry Soap mounted in paintroller fashion will clean walls and floors and windows and cars and furniture with wonderful speed and efficiency. It will need a somewhat spiky or corrugated surface, both to improve its reach into small crevices and to enlarge its dirt-capacity; even so it will soon get covered with grime. So the DREADCO team are giving it a low melting point. A used Dry Soap roller can simply be melted, and poured back into its corrugated-cylinder mould. The dirt diffuses into the bulk of the gel, and the cleaning surface is restored. When after much use the whole volume of the roller is saturated with dirt, a melt-filtering step regenerates a new roller, and recovers all the dirt. Nothing is wasted!

This elegant new technology saves water, reduces detergent effluent, and simplifies the cleaning process. Housewives and domestic cleaners everywhere should throw down their mops and brooms and buckets to welcome it with open arms. On the larger scale, big Dry Soap rollers hauled by tractors could clear grime and litter from streets and parks; while tiny ones might make ideal erasers for ink and ball-point writing. Dry Soap may even be suitable for cleaning clothes and fabrics. Of course, even the most convoluted sticky roller is not going to penetrate far into woven material. But dirt so deeply entrapped that it cannot be reached from the surface is presumably harmless anyway.

The personal-hygiene market is less promising. One volunteer likens washing with Dry Soap to kissing a sea-cucumber. It may simplify the task of washing a baby, but it will sell best to outdoor, agricultural and military users, far from the decadent luxuries of piped water and hot towels.

David Jones 